\title{
Clinical Implications of Snoring Time (\%) in Patients with Obstructive Sleep Apnea
}

\author{
Sun Uk Kim, Tae Wook Kang, Byung Ki Yoon, Ji Hye Choi, \\ Eui Suk Sung, Kyung Rae Kim, and Seok Hyun Cho \\ Department of Otorhinolaryngology-Head and Neck Surgery, Hanyang University College of Medicine, Seoul, Korea
}

\author{
폐쇄성 무호흡증 환자에서 코골이 시간(\%)의 임상적 의의 \\ 김선욱 · 강태욱 · 윤병기 · 최지혜 · 성의숙 · 김경래 · 조석현 \\ 한양대학교 의과대학 이비인후-두경부외과학교실
}

Received March 26, 2016

Revised July 11, 2016

Accepted July 13, 2016

Address for correspondence

Seok Hyun Cho, MD

Department of Otorhinolaryngology-

Head and Neck Surgery,

Hanyang University

College of Medicine,

222-1 Wangsimni-ro, Seongdong-gu,

Seoul 04763, Korea

Tel $+82-2-2290-8583$

Fax $+82-2-2293-3335$

E-mail shcho@hanyang.ac.kr
Background and Objectives Snoring is the vibration sound of respiratory structures when air stream flows through the narrowed airway during sleep. In this study, we aimed to determine the clinical meaning of snoring time (\%) of patients who have simple snoring or obstructive sleep apnea (OSA).

Materials and Methods We performed a retrospective review of 240 cases of clinical data and polysomnography, which were diagnosed with either simple snoring $(n=53)$ or OSA $(n=187)$. Clinical data included anthropometric measurements such as body mass index, neck and waist circumference (WC), and wasit-hip ratio (WHR). Snoring time (\%) was calculated as the total time of snoring per hour of sleep.

Results In the female group, snoring time (\%) increased in OSA compared to simple snoring, which showed a negative correlation with $\mathrm{N} 3(\mathrm{r}=-0.395, p=0.002)$ and a positive correlation with the arousal index $(r=0.39, p=0.003)$. Moreover, in females, snoring time $(\%)$ showed significant correlations with respiratory indexes: hypopnea index $(p=0.008)$, apnea-hypopnea index $(p=0.049)$, and lowest $\mathrm{SpO}_{2}(p=0.003)$. WC and WHR showed significant correlations with snoring time $(\%)$ in both male and female.

Conclusion Snoring time (\%) of females showed important clinical associations with sleep quality and respiratory index. Therefore, snoring may have an important role in the pathogenesis of OSA in females Korean J Otorhinolaryngol-Head Neck Surg 2016;59(9):649-54

\section{서 론}

폐쇄성 수면무호흡증(obstructive sleep apnea, OSA)은 성 인 인구의 $1 \sim 4 \%$ 가량 유병률을 보이며, 중년 이후 남성에서 호발한다. 임상적 증상으로 코골이와 호흡장애, 수면 분절과 과도한 주간졸림 등이 있으며, 환자 개인이 호소하는 이러한 증상들 외에 코골이는 배우자와 가족들에게 많은 불편감과 수면장애를 초래할 수 있다.

코골이는 성인 남성의 반 이상에서 습관적으로 나타나며 ${ }^{1)}$
수면 중 호흡 기류가 좁아진 기도를 지나면서 이완된 연구개 와 목젖, 인두벽 등의 주위 구조물에 진동을 일으켜 발생하 는 호흡 잡음을 말한다. ${ }^{2}$ 코골이는 유전적인 요인이 관여할 수도 있지만 노화, 폐경기 이후의 호르몬 이상, 비만 등의 생 리적인 요인도 그 원인으로 작용할 수 있다. ${ }^{3,4)}$ 또한 코골이는 자율신경계 자극을 통해 심혈관계나 호흡기계, 신경정신계 등의 전신적인 질환을 유발한다는 보고도 있으며 인슐린 저 항과 2형 당뇨병이 병인으로 작용할 수 있다. ${ }^{5)}$

폐쇄성 수면무호흡증의 경우 성별, 비만, 당뇨, 고혈압, 심장 
질환, 동맥경화증, 대사증후군 등의 인자들이 그 위험성을 증가시킨다는 많은 연구가 진행되어 왔으나 아직까지 코골이 와의 상관성에 대한 명확한 증거는 부족한 상태이다..$^{6-8)}$

코골이 정도를 객관적으로 측정하는 방법에는 수면다원검 사에서 코골이 강도(intensity)와 코골이 시간(snoring time, \%) 등이 있다. 코골이 강도는 폐쇄성 수면무호흡증의 중증도와 관련이 있다는 일부 연구들이 있었지만,9) 코골이 시간(snoring time, \%)에 대한 연구는 거의 없었으며, 또한 코골이 시간이 폐쇄성 수면무호흡증에서 어떤 임상적 의미를 가지는지에 대 한 연구도 거의 없었다.

이에 본 연구는 폐쇄성 수면무호흡증이 의심되어 시행한 수 면다원검사에서 코골이 시간과 다른 객관적 지표 외에 비만 지수를 포함한 여러 가지 임상변수와의 통계적 분석을 통하 여 어떠한 임상적 의미가 있는지 알아보고자 하였다.

\section{대상 및 방법}

\section{연구 대상}

2013년 2월부터 2015년 3월까지 본원 이비인후과에 코골이 및 과다한 주간졸림증을 주소로 내원한 외래 환자들 중 임 상적으로 폐쇄성 수면무호흡증이 의심되어 수면다원검사를 시행한 240명의 환자들을 대상으로 후향적 연구를 시행하였 다. 수면다원검사에서 무호흡-저호흡 지수(apnea-hypopnea index, AHI)가 5 미만일 때를 단순 코골이군(정상군)으로, AHI가 5 이상일 때를 OSA군으로 분류하였다.

의무기록을 통해 연구에 포함된 환자들의 나이, 성별, 흡연 력, 고혈압, 당뇨 등의 병력을 조사하였고, 수면다원검사 당일 측정한 체질량 지수(body mass index, BMI), 목둘레(neck circumference), 허리-엉덩 둘레비(waist-hip ratio, WHR)의 비만지수를 확인하였다.

기면증, 과다수면, 주기성 사지 운동장애, 비만성 저환기 증 후군으로 의심되는 환자 또는 신경과적, 정신과적 이상이 있거 나 다른 전신질환이 있는 환자들은 연구대상에서 제외되었다.

수면관련 증상은 Pittsburgh Sleep Quality Index(PSQI) 를 이용하였고, 주간졸림증에 대한 평가는 Epworth Sleepiness Scale(ESS)를 이용하였다. ${ }^{10,11)}$

\section{수면다원검사(Polysomnography)}

연구에 포함된 모든 환자들에 대해 수면다원검사를 시행 하였고, 수면다원검사(Alice 5; Respironics, Murrysville, $\mathrm{PA}, \mathrm{USA})$ 는 표준화된 방법에 따라 심전도, 안전도, 뇌파, 하 악근전도, 하지근전도, 비강 및 구강 서미스터를 통한 공기흐 름과 압력, 혈중 산소포화도, 흥복부 운동, 그리고 체위 변화
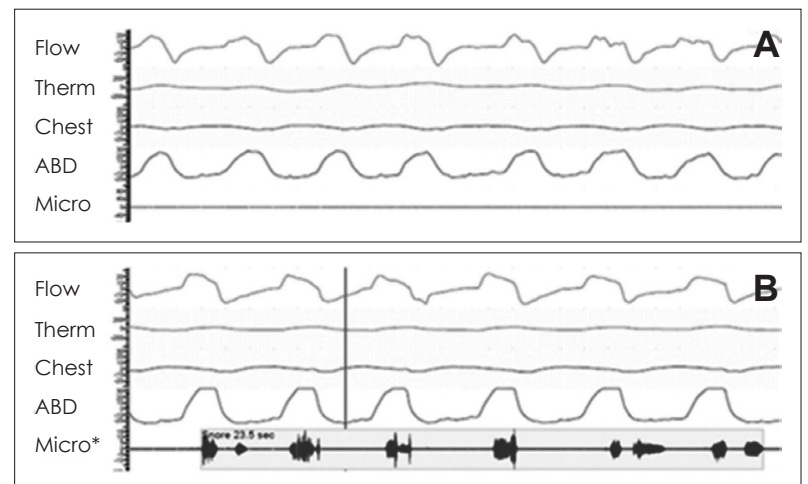

Fig. 1. Snoring events are easily identified by a series of marked acoustic waves sensed by the microphone sensor. Linear signal of the microphone shows no snoring event $(A)$ and several events of snoring are noted during 6 cycles of respiration (B). We defined the snoring interval as the respiratory cycles accompanied with snoring events. *microphone.

와 함께 수면 단계를 측정하였다.

무호흡은 구강 또는 비강으로 측정하는 기류가 10 초 이상 $90 \%$ 이상 떨어질 때로 정의하였다. 저호흡은 1) 저호흡 발생 전 비강이나 구강으로 측정하는 호흡량이 10 초 이상 $50 \%$ 이 상 감소하거나, 2) 산소포화도가 저호흡 발생 시 $3 \%$ 이상 감소 할 때 또는 3) 저호흡이 뇌파의 각성과 연관이 있을 때로 하였 다. AHI는 무호흡 지수(apnea index)와 저호흡 지수(hypopnea index)의 합으로 계산하였다. 코골이 시간(snoring time, $\%)$ 은 코를 곤 시간을 총 수면 시간으로 나누어 백분율을 표 시하였다. ${ }^{12)}$

코골이에 대한 정의는 아직까지 가이드라인에 명시된 적이 없고, 병원마다 서로 다른 기준을 사용하고 있다. 코골이 구간 은 기저파와 비교하여 육안으로 확연하게 알 수 있는 일련의 진동파로 판독을 하고, 1 회 이상의 코골이를 동반하지 않는 정상 호흡곡선으로 분절되는 경우 독립된 코골이 구간으로 정의하였다(Fig. 1).

\section{통계 분석}

정규성 검정(Shapiro-Wiky)에서 데이터가 비정규분포함에 따라 중앙값(median)과 사분위수(interquartile range)로 표시 하였다. 양 군 간의 차이분석은 비모수검정인 Mann-Whitney $\mathrm{U}$ 검사를 이용하였다. 코골이 시간(snoring time, \%)과 관련 이 있는 유의한 변수들을 찾기 위하여 Pearson correlation analysis를 이용하였으며 모든 통계 분석은 SPSS version 22(version 22.0 for windows; SPSS Inc., Chicago, IL, USA) 를 이용하였다. 통계학적 유의성은 유의확률 0.05 미만을 기 준으로 하였다. 


\section{결 과}

수면무호흡증이 의심되어 수면다원검사를 시행받은 183 명 의 남성에서 OSA로 진단된 경우는 156명(85.2\%)이었고, 57명 의 여성 중에서 OSA로 진단된 경우는 31명(54.4\%)이었다 (Table 1). 남녀 모두에서 단순 코골이군에 비하여 OSA군의 평균 연령이 더 높았다. 또한 남녀 모두 단순 코골이군과 OSA 군은 흡연, 고혈압과 당뇨 등의 전신질환의 차이를 보이지 않 았고, ESS와 PSQI 설문조사도 비슷하였다.

비만에 관계된 신체계측(anthropometry)에서 목둘레( $p=$ $0.007)$ 와 $\operatorname{WHR}(p=0.003)$ 은 남성 $\mathrm{OSA}$ 에서 증가하였고, $\mathrm{BMI}$ $(p=0.01)$ 와 $\operatorname{WHR}(p=0.001)$ 은 여성 $\mathrm{OSA}$ 에서 증가하였다.

수면다원검사의 수면관련 지표에서 남성 OSA군은 단순 코골이군에 비하여 나쁜 수면효율을 보인 반면 $(p=0.019)$, 여 성에서는 차이를 보이지 않았다(Table 2). 남성 OSA에서는 깊은 잠 $(\mathrm{N} 3 \%, p=0.027)$ 이 대조군에 비하여 감소했고, 남녀 모두에서 OSA군의 각성지수는 단순 코골이군에 비하여 의 미있게 증가하였다 $(p=0.001)$.
수면다원검사의 호흡관련 지표에서 무호흡지수, 무호흡저호흡지수 및 최저산소포화도는 남녀 모두에서 OSA군과 단순 코골이군 사이에 통계적으로 의미 있는 차이를 보였다 $(p<0.05)$. 코골이 시간 $(\%)$ 은 남성에서는 차이가 없었으나 $(p=0.068)$, 여성 OSA군은 단순 코골이군에 비하여 코골이 시간이 의미 있게 증가하였다 $(p=0.006)$.

코골이 시간(\%)의 임상적 의미를 알기 위해 여러 임상변수와 수면다원검사 결과값과의 상관분석을 시행한 결과, 남성에서 는 어떠한 변수도 유의한 상관성을 보이지 않았다(Table 3). 그러나 여성에서는 연령 $(\mathrm{r}=0.277, p=0.037)$ 및 각성지수 $(\mathrm{r}=0.39$, $p=0.003)$ 와 양의 상관성을 보였고, 깊은 잠과는 음의 상관성 $(\mathrm{r}=-0.395, p=0.002)$ 을 보였다.

코골이 시간(\%)과 비만의 관계를 알아보기 위해 상관분석 을 시행한 결과, 남녀 모두에서 허리둘레와 WHR은 코골이 시 간과 양의 상관성을 보였으나, 체질량지수와는 상관성을 보 이지 않았다(Fig. 2). 목둘레는 여성과 달리 남성에서 코골이 시간과 양의 상관관계를 보였다( $\mathrm{r}=0.187, p=0.011)$.

코골이 시간(\%)과 다른 호흡장애지수와의 연관성을 알아보

Table 1. Gender effects on anthropometric differences between OSA and snoring patients

\begin{tabular}{|c|c|c|c|c|c|c|}
\hline & \multicolumn{2}{|c|}{ Male $(n=183)$} & \multirow{2}{*}{$p$ value } & \multicolumn{2}{|c|}{ Female $(n=57)$} & \multirow{2}{*}{$p$ value } \\
\hline & OSA $(n=156)$ & Snoring $(n=27)$ & & OSA $(n=31)$ & Snoring $(n=26)$ & \\
\hline \multicolumn{7}{|l|}{ Clinical } \\
\hline Age & $43.2(13.3)$ & $36.8(13.8)$ & 0.028 & $52.5(11.7)$ & $41.1(13.4)$ & 0.001 \\
\hline Smoking (\%) & 33.3 & 22.2 & 0.370 & 3.2 & 11.5 & 0.322 \\
\hline HTN (\%) & 36.5 & 18.5 & 0.080 & 35.5 & 11.5 & 0.062 \\
\hline DM (\%) & 13.5 & 3.7 & 0.207 & 11.5 & 0 & 0.242 \\
\hline ESS & $9(4.3-13.8)$ & $11(7-14)$ & 0.095 & $7(4-13)$ & $7.5(5.8-14.3)$ & 0.499 \\
\hline PSQI & $7(5-10)$ & $9(7.3-11)$ & 0.073 & $9(6.3-13.8)$ & $8(6-10)$ & 0.553 \\
\hline \multicolumn{7}{|l|}{ Anthropometry } \\
\hline BMI $\left(\mathrm{Kg} / \mathrm{m}^{2}\right)$ & $25.9(24.2-28.3)$ & $25.3(22-27.9)$ & 0.091 & $23.7(22.3-29.8)$ & $22.5(20.5-24.2)$ & 0.01 \\
\hline $\mathrm{NC}(\mathrm{cm})$ & $40(38-42)$ & $38(36-40)$ & 0.007 & $33.5(32-37)$ & $33.3(32.4-35)$ & 0.298 \\
\hline WHR & $0.94(0.9-0.98)$ & $0.89(0.86-0.96)$ & 0.003 & $0.9(0.88-0.94)$ & $0.86(0.83-0.89)$ & 0.001 \\
\hline
\end{tabular}

All values are reported as median (interquartile range). OSA: obstructive sleep apnea, HTN: hypertension, DM: diabetes mellitus, ESS: Epworth Sleepiness Scale, PSQI: Pittsburgh Sleep Quality Index, NC: neck circumference, WHR: waist hip ratio

Table 2. Gender effects on polysomnographic differences between OSA and snoring patients

\begin{tabular}{|c|c|c|c|c|c|c|}
\hline & \multicolumn{2}{|c|}{ Male $(n=183)$} & \multirow{2}{*}{$p$ value } & \multicolumn{2}{|c|}{ Female $(n=57)$} & \multirow{2}{*}{$p$ value } \\
\hline & OSA $(n=156)$ & Snoring $(n=27)$ & & OSA $(n=31)$ & Snoring $(n=26)$ & \\
\hline \multicolumn{7}{|l|}{ Polysomnography } \\
\hline SE $(\%)$ & $79.8(68.8-87.6)$ & $83.3(79.7-91.4)$ & 0.019 & $82.6(71.3-90.5)$ & $82.9(77.1-92.6)$ & 0.586 \\
\hline N3 (\%) & $0(0-2.7)$ & $2.6(0-6.5)$ & 0.027 & $0(0-9.2)$ & $2.8(0-12.6)$ & 0.115 \\
\hline Snoring time (\%) & $45.8(31-66.1)$ & $37.9(17.4-56.9)$ & 0.068 & $47.1(33.3-62.5)$ & $18.9(5.7-49.2)$ & 0.006 \\
\hline $\mathrm{Al}$ & $9.6(2.1-27.3)$ & $0.4(0.2-0.9)$ & 0.001 & $1.5(0.4-8.3)$ & $0.7(0.2-1.3)$ & 0.004 \\
\hline $\mathrm{AHI}$ & $27(13.2-51.9)$ & $1.8(1.2-4.1)$ & 0.001 & $13.3(7.4-30.1)$ & $1.6(0.8-3.1)$ & 0.001 \\
\hline Lowest $\mathrm{O}_{2}(\%)$ & $83(76-88)$ & $92(90-94)$ & 0.001 & $83(80-89)$ & $92(89.8-94)$ & 0.001 \\
\hline Arousal index & $27.1(9.6-21.9)$ & $13.7(9.6-21.9)$ & 0.001 & $18.1(12-32.9)$ & $11.1(7.7-15.9)$ & 0.001 \\
\hline
\end{tabular}

All values are reported as median (interquartile range). SE: sleep efficiency, N3: deep sleep, OSA: obstructive sleep apnea, Al: apnea index, AHI: apnea-hypopnea index 
기 위해 상관분석을 시행한 결과, 남성의 무호흡지수, 저호흡 지수, 무호흡-저호흡지수 및 최저산소포화도는 코골이 시간 과 연관성을 보이지 않았다(Fig. 3). 그러나 여성에서 저호흡 지수 $(\mathrm{r}=0.346, p=0.008)$ 와 무호흡-저호흡지수 $(\mathrm{r}=0.262, p=$ 0.049)는 코골이 시간과 양의 상관성을 보였고, 최저산소포

Table 3. Correlation of snoring time (\%) with clinical and sleep parameters in men and women

\begin{tabular}{lrlllll}
\hline & \multicolumn{2}{c}{ Male } & & \multicolumn{2}{c}{ Female } \\
\cline { 6 - 7 } \cline { 5 - 6 } & & p value & & $r$ & p value \\
\hline Clinical parameters & & & & & \\
$\quad$ Age & 0.047 & 0.407 & & 0.277 & $0.037^{*}$ \\
ESS & -0.021 & 0.775 & & -0.063 & 0.643 \\
PSQI & 0.055 & 0.493 & & -0.008 & 0.959 \\
Sleep parameters & & & & & \\
N3 (\%) & -0.139 & 0.060 & & -0.395 & $0.002^{\dagger}$ \\
REM (\%) & -0.061 & 0.416 & & 0.072 & 0.593 \\
Arousal index & -0.024 & 0.746 & & 0.390 & $0.003^{\dagger}$ \\
\hline
\end{tabular}

$* p<0.05,{ }^{\dagger} p<0.01$. Numbers are Pearson's correlation coefficient ( $r$ values). ESS: Epworth Sleepiness Scale, PSQI: Pittsburgh Sleep Quality Index, REM: rapid eye movement 화도(r=-0.384, $p=0.003)$ 는 음의 상관성을 보였다.

\section{고 찰}

코골이는 OSA를 대변하는 대표적인 증상으로 알려져 있 지만, OSA 환자에 있어서 코골이 자체가 갖는 임상적인 의의 에 대해서는 아직 논쟁이 되는 부분들이 있다. 그 중 수면다원 검사상 코골이 강도(intensity)는 OSA의 중증도와 관련이 있 다는 일부 연구가 있었지만,1,13) 코골이 시간(\%)에 대해 중점적 으로 다룬 연구는 거의 없었다. OSA 환자에서는 구개 및 구 인두의 구조물로부터 발생하는 수축과 진동이 단순 코골이 군(수면다원검사상 정상군)에 비해 그 빈도가 더 많을 것이므 로 $^{14)}$ 코골이 시간 자체 역시 증가하리라 예상된다. 이에 코골 이 시간(\%)이 수면다원검사에서 OSA 환자들에게 어떤 임상 적 의의가 있는지 알아보고자 하였다.

본 연구에서 목둘레는 여성의 경우 단순 코골이군과 OSA 군 사이에서 뚜렷한 차이는 없었고, 코골이 시간(\%)에 영향을 미치지 않았다. 그러나 남성의 경우 OSA군이 유의하게 목둘
Fig. 2. Effect of obesity indexes on snoring time \%. (A) Body mass index, (B) neck circumference (C) waist circumference, and waist-hip ratio (D).
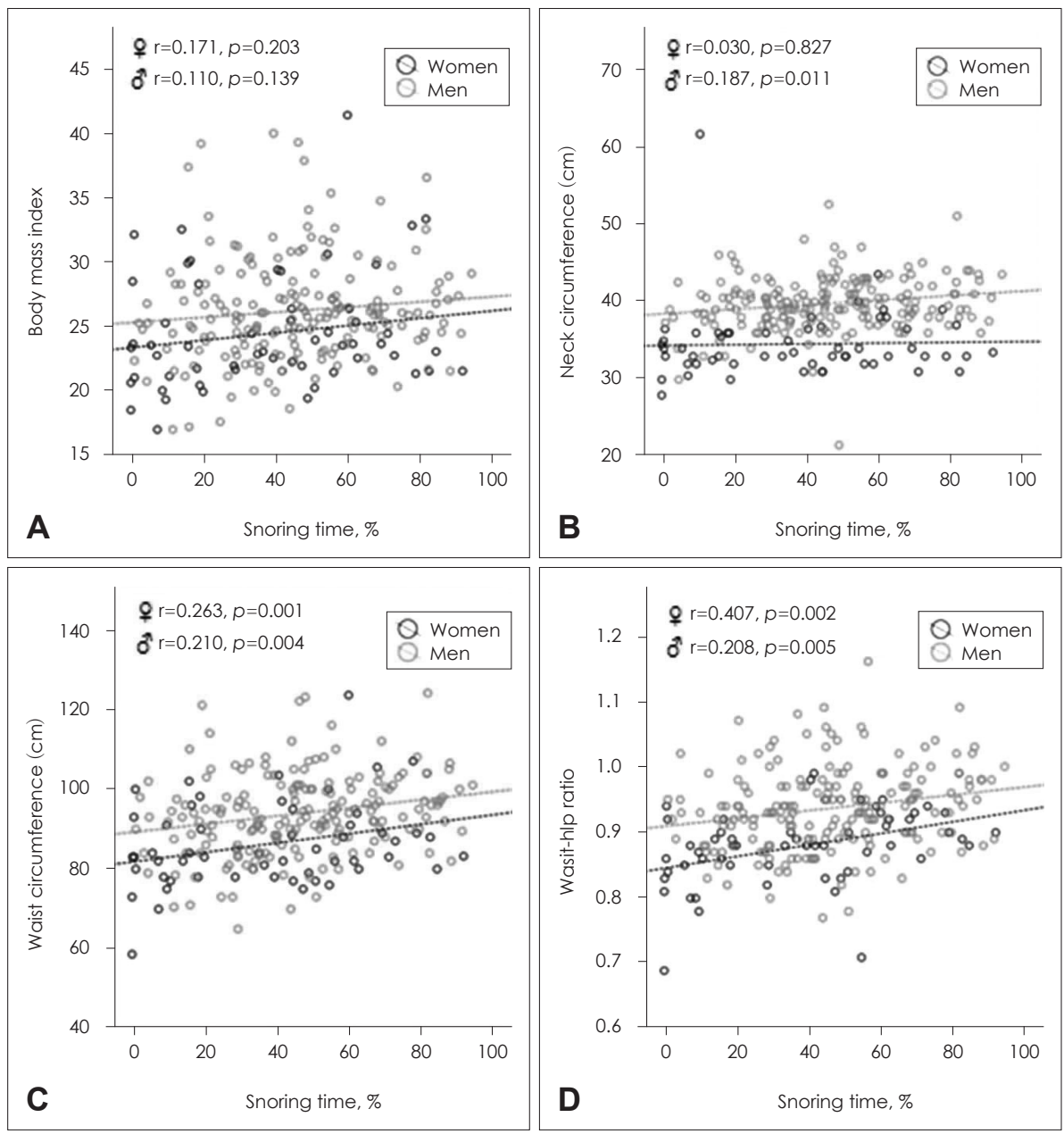

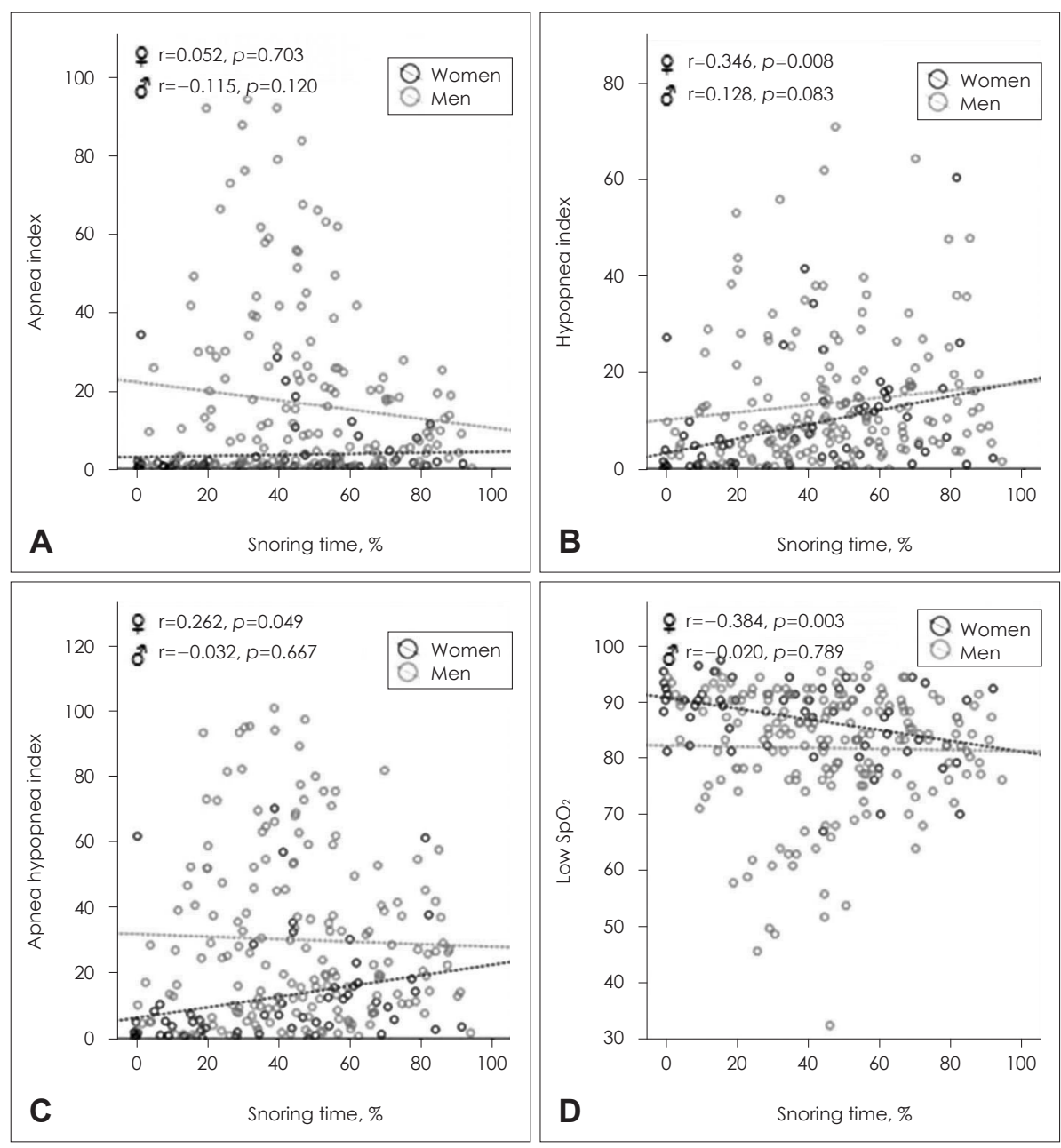

Fig. 3. Association between snoring time $\%$ and respiratory parameters. (A) Apnea index, (B) hypopnea index, (C) apnea-hypopnea index, and (D) lowest $\mathrm{SpO}_{2}$.

레 길이가 길었고, 코골이 시간과 양의 상관성을 보여 비만으 로 인한 목 지방의 증가는 코골이를 포함한 기도폐쇄에 관여 하는 것으로 볼 수 있다.15,16)

수면무호흡증과 코골이가 없는 정상인 사이에서 $\mathrm{BMI}$ 는 절대적인 영향을 미친다는 결과는 많이 보고되어 왔다. ${ }^{17)}$ 본 연구에서는 여성 OSA에서만 BMI가 유의하게 증가하였고, 남녀 모두에서 코골이시간과 연관성을 보이지 않았다. 그러 나 허리둘레와 WHR은 남녀 모두에서 코골이 시간(\%)과 양의 상관성 $(<0.005)$ 을 보였고, 이는 중심성 비반지표인 허리둘레 와 WHR은 성별에 상관없이 코골이 및 OSA와 깊은 연관성을 가지는 것으로 이해할 수 있다.

Gottlieb 등 ${ }^{18}$ 은 설문지를 통해 일주일에 코골이를 하는 날짜수를 체크하였고, ESS 설문지와 함께 코골이 빈도가 과 도한 졸음과 관련이 있음을 보고한 바 있다. 특히 수면 무호 흡증이 없는 사람들 중 코를 고는 환자들이 코를 골지 않는 환자들에 비해 과도한 주간 졸음을 호소하였다고 보고하였 다. 본 연구에서 시행한 $\mathrm{PSQI},{ }^{10)} \mathrm{ESS}^{11)}$ 설문지상 코골이군과 폐쇄성 수면무호흡증군 사이에 수면의 질적 차이는 존재하
지 않았다. 또한 코골이 시간과 수면의 질, 주간 졸음과도 상 관관계는 없었다. 본 연구의 연구 대상자는 총 240명으로 Gottlieb 연구에 비해 그 수가 적었지만, 환자가 호소한 주관 적 정보로서의 주중 코를 고는 날짜수를 코골이 빈도로서 측정하였던 Gottlieb 연구와는 달리 객관적인 수면다원검사 의 코골이 시간(\%)을 측정하였다는 차이가 있다.

Vagiakis 등 19 은 남성에서 여성보다 AHI가 더 높게 측정되 었지만, rapid eye movement 수면일 때에는 여성이 남성보다 $\mathrm{AHI}$ 가 더 높게 나타났음을 보고하였고, 이는 수면 주기와 관 련하여 호흡 사건에 영향을 미칠 수 있다고 보고하였다. 본 연 구에서도 수면 상태와 코골이 시간(\%)과의 연관성을 살펴보 았으며 여성에서는 깊은 수면과는 유의한 음의 상관관계를, 각성지표와는 유의한 양의 상관관계를 보였다. 이는 여성에 서 남성보다 체지방의 분포 및 긴 인두길이 등 ${ }^{20}$ 의 해부학적 인 불리함이 적어 코골이가 각성의 원인으로 작용한 것으로 생각된다. 더불어 코골이가 깊은 잠을 방해하여 수면의 질을 떨어뜨리는 역할을 한다는 것을 의미하며, 다른 호흡장애와 유의한 연관성을 보임을 알 수 있었다. 
본 논문에서 참여한 연구 대상자들은 총 240 명으로 그 중 단순 코골이군은 53명으로 그 수가 적었다. 더욱이 코골이 시 간(\%)과 각 변수의 연관성을 고찰함에 있어서 남녀를 나누었 기 때문에, 연구 대상자들 수는 전체를 대변하기에 한계가 있 을 수 있다고 생각된다. 또한 본 연구는 코골이 시간(\%)이 각 변수들과의 의미 있는 상관관계 속에서 OSA와 관계가 있을 수 있고 나아가 OSA의 중증도와도 관련이 있을 수 있음을 강조하였지만 OSA는 다양한 요인들이 복합적으로 작용하는 질환이다. 따라서 추후 연구에서는 많은 연구 대상자와 함께 다변량 분석이 함께 이루어질 필요가 있으며 코골이의 병인 에 대해 정확한 분석이 필요하다고 생각된다.

\section{REFERENCES}

1) Levartovsky A, Dafna E, Zigel Y, Tarasiuk A. Breathing and snoring sound characteristics during sleep in adults. J Clin Sleep Med 2016; 12(3):375-84.

2) Herzog M, Schieb E, Bremert T, Herzog B, Hosemann W, Kaftan $\mathrm{H}$, et al. Frequency analysis of snoring sounds during simulated and nocturnal snoring. Eur Arch Otorhinolaryngol 2008;265(12): 1553-62.

3) Lee LH, Lee SJ, Kang HW. Gender differences in the polysomnographic findings among obstructive sleep apnea patients. Korean J Otorhinolaryngol-Head Neck Surg 2012;55(2):90-4.

4) Park KM, Nam WH, Lim EJ, Song SH, Lee HW, Kim JS. Correlation analysis between self-reported measures in patients with OSA. Korean J Otorhinolaryngol-Head Neck Surg 2007;50(10):888-95.

5) Reichmuth KJ, Austin D, Skatrud JB, Young T. Association of sleep apnea and type II diabetes: a population-based study. Am J Respir Crit Care Med 2005;172(12):1590-5.

6) Chung YS, Kim JH, Park HW, Kim JM, Park YG, Kim YJ, et al. Prevalence of the associated diseases in patients with snoring and sleep apnea. Korean J Otolaryngol-Head and Neck Surg 2001;44 (3):283-7.

7) Eun YG, Kim SW, Kim MG, Cho JS. Clinical predictor in obstructive sleep apnea patient. Korean J Otolaryngol-Head and Neck Surg 2006;49(6):616-22.

8) Kang JM, Kang SG, Lee YJ, Jeong JH, Kang IG, Hwang HY, et al. Personality characteristics of patients with obstructive sleep apnea and simple snoring: a preliminary study. Sleep Med Psychophysiol 2014;21(1):21-8.
9) Kim JW, Lee CH, Rhee CS, Mo JH. Relationship between snoring intensity and severity of obstructive sleep apnea. Clin Exp Otorhinolaryngol 2015;8(4):376-80.

10) Buysse DJ, Reynolds CF 3rd, Monk TH, Berman SR, Kupfer DJ. The pittsburgh sleep quality index: a new instrument for psychiatric practice and research. Psychiatry Res 1989;28(2):193-213.

11) Smith SS, Oei TP, Douglas JA, Brown I, Jorgensen G, Andrews J. Confirmatory factor analysis of the Epworth Sleepiness Scale (ESS) in patients with obstructive sleep apnoea. Sleep Med 2008;9(7):73944.

12) Berry RB, Budhiraja R, Gottlieb DJ, Gozal D, Iber C, Kapur VK, et al. Rules for scoring respiratory events in sleep: update of the 2007 AASM Manual for the Scoring of Sleep and Associated Events. Deliberations of the Sleep Apnea Definitions Task Force of the American Academy of Sleep Medicine. J Clin Sleep Med 2012;8 (5):597-619.

13) Maimon N, Hanly PJ. Does snoring intensity correlate with the severity of obstructive sleep apnea? J Clin Sleep Med 2010;6(5): 475-8.

14) Herzog M, Schmidt A, Bremert T, Herzog B, Hosemann W, Kaftan $\mathrm{H}$. Analysed snoring sounds correlate to obstructive sleep disordered breathing. Eur Arch Otorhinolaryngol 2008;265(1):105-13.

15) Wysocki J, Charuta A, Kowalcze K, Ptaszyńska-Sarosiek I. Anthropometric and physiologic assessment in sleep apnea patients regarding body fat distribution. Folia Morphol (Warsz) $2015 \mathrm{Dec}$ 29 [Epub ahead of print]. http://dx.doi.org/10.5603/FM.a2015.0127.

16) Kawaguchi Y, Fukumoto S, Inaba M, Koyama H, Shoji T, Shoji S, et al. Different impacts of neck circumference and visceral obesity on the severity of obstructive sleep apnea syndrome. Obesity (Silver Spring) 2011;19(2):276-82.

17) Shin C, Kang HG, Lee SD, Jung DK, Park SO, Park JH. Relationship between manual cephalo-anthropometric analysis and degree of snoring in Korean adult. Korean J Otolaryngol-Head Neck Surg 2001;44(2):172-7.

18) Gottlieb DJ, Yao Q, Redline S, Ali T, Mahowald MW. Does snoring predict sleepiness independently of apnea and hypopnea frequency? Am J Respir Crit Care Med 2000;162(4 Pt 1):1512-7.

19) Vagiakis E, Kapsimalis F, Lagogianni I, Perraki H, Minaritzoglou A, Alexandropoulou K, et al. Gender differences on polysomnographic findings in Greek subjects with obstructive sleep apnea syndrome. Sleep Med 2006;7(5):424-30.

20) Dobrowolska-Zarzycka M, Dunin-Wilczyńska I, Szymańska J. Craniofacial structure in patients with obstructive sleep apnoea. Folia Morphol (Warsz) 2016 Jan 25 [Epub ahead of print]. http:// dx.doi.org/10.5603/FM.a2016.0003. 